\title{
Measuring the Healthiness of Ready-to-Eat Child-Targeted Cereals: Evaluation of the FoodSwitch Platform in Sweden
}

Antoine Mottas ${ }^{1}$, MSc; Veli-Matti Lappi ${ }^{1}$, MSc, MD; Johan Sundström ${ }^{2,3}, \mathrm{MD}, \mathrm{PhD}$; Bruce Neal ${ }^{3,4}, \mathrm{MBChB} \mathrm{PhD}$; Cliona Ni Mhurchu ${ }^{3,5}$, BSc (Hons), PhD; Marie Löf ${ }^{1,6}, \mathrm{PhD}$; Karin Rådholm ${ }^{3,6}, \mathrm{MD}, \mathrm{PhD}$

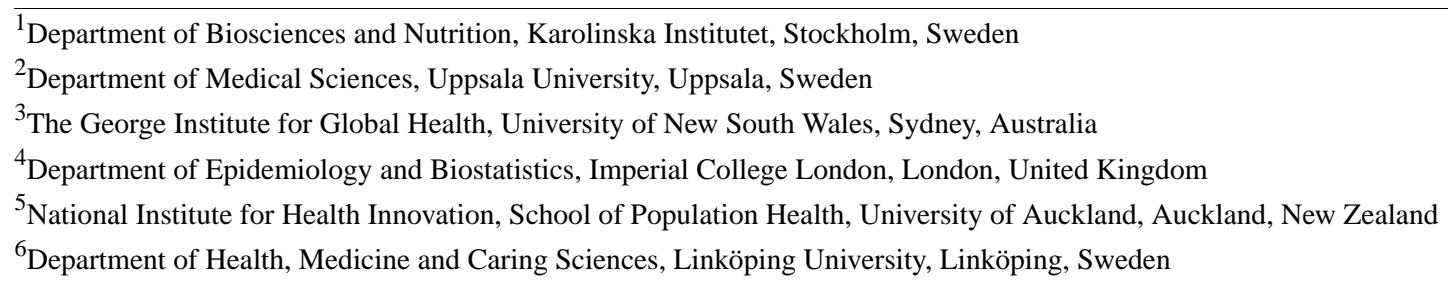

Corresponding Author:

Karin Rådholm, MD, PhD

Department of Health, Medicine and Caring Sciences

Linköping University

Linköping, SE-58183

Sweden

Phone: 4613281756

Email: karin.radholm@liu.se

\section{Abstract}

Background: Childhood obesity is a major public health issue. The increase in the consumption of foods with poor nutritional value, such as processed foods, contributes to this. Breakfast cereals are often advertised as a healthy way to start the day, but the healthiness of these products varies greatly.

Objective: Our main objective was to gather information about the nutritional characteristics of ready-to-eat breakfast cereals in Sweden and to investigate the healthiness of products targeted at children compared to other cereals by use of the FoodSwitch platform. A secondary objective was to evaluate the alignment between the Keyhole symbol and the Health Star Rating.

Methods: The FoodSwitch app is a mobile health (mHealth) tool used to present nutrition data and healthier alternative products to consumers. Ready-to-eat breakfast cereals from the largest Swedish grocery retailers were collected using the FoodSwitch platform. Products were defined as targeting children if they presented features addressing children on the package.

Results: Overall, information on 261 ready-to-eat cereals was examined. Of this total, $8 \%(n=21)$ were targeted at children. Child-targeted cereals were higher in sugar $(22.3 \mathrm{~g} / 100 \mathrm{~g}$ vs $12.8 \mathrm{~g} / 100 \mathrm{~g}, P<.001)$ and lower in fiber $(6.2 \mathrm{~g} / 100 \mathrm{~g}$ vs $9.8 \mathrm{~g} / 100$ $\mathrm{g}, P<.001)$ and protein $(8.1 \mathrm{~g} / 100 \mathrm{~g}$ vs $10.5 \mathrm{~g} / 100 \mathrm{~g}, P<.001)$. Total fat $(3 \mathrm{~g} / 100 \mathrm{~g}$ vs $10.5 \mathrm{~g} / 100 \mathrm{~g}, P<.001)$ and saturated fat $(0.8$ $\mathrm{g} / 100 \mathrm{~g}$ vs $2.6 \mathrm{~g} / 100 \mathrm{~g}, P<.001)$ were also lower. No difference was found in salt content $(P=.61)$. Fewer child-targeted breakfast cereals displayed an on-pack Keyhole label $(\mathrm{n}=1,5 \%$ vs $\mathrm{n}=53,22 \% ; P=.06)$, and the mean Health Star Rating value was 3.5 for child-targeted cereals compared to others (mean 3.8, $P=.07$ ). A correlation was found between the Keyhole symbol and the Health Star Rating.

Conclusions: Ready-to-eat breakfast cereals targeted at children were less healthy in terms of sugar and fiber content compared to products not targeted at children. There is a need to improve the nutritional quality of child-targeted cereals.

(JMIR Mhealth Uhealth 2021;9(7):e17780) doi: $\underline{10.2196 / 17780}$

\section{KEYWORDS}

breakfast cereals; child-targeted cereals; front-of-pack labels; Keyhole symbol; Health Star Rating; FoodSwitch; diet; food intake 


\section{Introduction}

Childhood obesity is a major public health issue. Over 40 million children under 5 years of age are overweight worldwide with a majority living in low- or middle-income countries [1]. The increasing rates of obesity in children are linked to noncommunicable diseases such as type 2 diabetes and cardiovascular diseases in young adults [2]. In addition, individuals with obesity at an early age are more prone to obesity later in life [3]. Unhealthy diet is the leading risk factor for obesity in children and adults. Processed foods, which are energy dense and of poor nutritional value, are a major cause of obesity [4]. In the last few decades, the consumption of processed and ultraprocessed food has increased and correlates with the elevated prevalence of obesity [5].

Ready-to-eat breakfast cereals include a large range of products from unprocessed to ultraprocessed. This large diversity in products and the omnipresence of nutritional claims on the packages of breakfast cereals make it hard for the consumer to identify actual healthy options. In addition, there are data suggesting that highly advertised products targeted at children may be less healthy [6]. To help consumers, front-of-pack nutrition labels have been created. There are many types of labeling, often specific to a country or area, but all aim to promote healthier food choices and, in the long term, to urge manufacturers to reformulate their products [7]. The Swedish National Food Administration introduced the Keyhole symbol that endorses products with healthier fat composition, less sugars and salt, and more dietary fiber, whole grains, fruits, and vegetables than other similar foods [8]. The Health Star Rating (HSR), developed by the Australian government, grades foods from 0.5 to 5 stars [9]. Grades are attributed based on energy content, saturated fat, sugar, salt, protein, fiber, as well as fruit, vegetable, nut, and legume content, in the product. In other countries different front-of-pack labels are used. For instance, nutrient-specific labels that assess the percentage of each nutrients (eg, Traffic Lights labeling and nutrient-specific warnings that indicate an excessive amount of critical nutrients). The weakness of most systems is that they remain voluntary and rely on industry interest. In addition, the coexistence of numerous front-of-pack labels in the marketplace, as well as the great disparity between their criteria, can be confusing for consumers [10].

The use of mobile apps could be an innovative alternative way for consumers to access more information on the nutrients and healthiness of the foods they buy. Today, $88 \%$ of people in Sweden over the age of 12 years own a smartphone, which offers great potential for mobile health (mHealth) apps in all age groups [11]. The FoodSwitch app, developed by the George Institute for Global Health in Australia, was designed to offer a tool to promote healthier food choices and is currently being used in Australia, New Zealand, China, the United Kingdom, India, the United States, Kuwait, South Africa, Fiji, and Hong Kong. By scanning bar codes of packaged foods, the consumer obtains at-a-glance information on the product as well as suggestions of similar healthier products [12]. The FoodSwitch solution includes the FoodSwitch app, a database with packaged products organized in a categorized system that is applicable to all countries and enables comparisons, and a data collection application (DataCollector). The FoodSwitch database has been previously used in several studies to measure the healthiness of packaged food, to evaluate variations in specific nutrients, and to compare front-of-pack labeling systems [13-15].

In this study, we aim to use the FoodSwitch platform in the Swedish market to compare the healthiness and nutritional values of ready-to-eat breakfast cereals targeted at children to non-child-targeted, ready-to-eat cereals. Furthermore, we aim to assess the alignment of the Nordic Keyhole symbol and the HSR system for these products.

\section{Methods}

\section{Data Collection}

Ready-to-eat cereals from 4 supermarkets (ICA, Coop, Hemköp, and Lidl), representing $90 \%$ of the market share in Sweden, were analyzed [16]. The largest supermarkets in the Stockholm area were targeted to ensure the presence of the entire range of products. Prior to data collection, which took place in February and March 2019, consent forms were sent to the store managers. One store denied us permission without giving more details on why they chose to do so, and thus this retailer was not included. On site, the cereal department and all shelves containing breakfast cereals, including gluten-free sections, were identified. Oatmeal for porridge was regarded as a grain and not used as a breakfast cereal per se. Muesli, however, was included. There is a thin line between cereal bars and candy, and cereal bars are categorized differently from breakfast cereal on the FoodSwitch platform. Thus, they were not deemed breakfast cereal and were excluded.

The DataCollector app of the FoodSwitch platform (Android, version 2.7) from the George Institute for Global Health was used to collect information from packages. First, the bar codes were scanned using a smartphone camera. Then, numerous pictures of the front of the pack, the Nutrition Information Panel (NIP), and the ingredients were taken to collect all relevant information.

All products were manually entered in the system by 1 researcher (AM). The NIP, the gluten status and the Keyhole symbol, if present, were recorded. All child-targeted information on the package was identified. The criteria were as follows: the presence of cartoons, games, toys, children's movie references, or text addressed to children on the package. A second researcher (V-ML) reviewed all the information entered and confirmed the presence of marketing targeted at children.

Finally, products were categorized and an HSR was generated. HSR scores of 0.5 to 5 stars in 10 half-star increments were assigned to all scanned products, where a higher number of stars represents healthier products. In the HSR system, each packaged food item is categorized into 1 of 6 categories depending on food type. All breakfast cereals were assigned to category 2. The HSR score was calculated via baseline and modifying points using the following formula: HSR score = baseline points modifying points. Baseline points depended on energy content, saturated fat, sugar, and salt, and modifying points were based on protein, fiber, fruit, and vegetable content. The final 
assignment of the HSR score depended on which category the product was assigned to [17].

\section{Statistical Analysis}

Categorical variables were summarized as the number of products and corresponding percentages, and continuous variables were summarized as mean (SD) and median (IQR). A Kolmogorov-Smirnov test was used to determine whether the data were normally distributed or not. A Mann-Whitney $U$ test and an independent-samples $t$ test were used to compare the nutritional values and HSR of child-targeted cereals to the nontargeted ones for nonnormal and normal distribution, respectively. In addition, the HSR scores were divided into two groups, healthier $(\mathrm{HSR} \geq 3.5)$ and less healthy (HSR <3.5) [18]. After dichotomization of HSR scores, the Fisher exact test was performed to assess correlation to the presence of the Keyhole symbol. The significance level was set to $P<.05$. The statistical analysis was performed using SPSS Statistics 25 (IBM Corp).

\section{Ethical Considerations}

This was a study of packaged food supplies in supermarkets in Sweden and did not involve study participants or animal testing. Therefore, no ethical permission was sought.

\section{Results}

By use of the data collection application of the FoodSwitch platform, we collected information on a total of 261 ready-to-eat breakfast cereals, of which $21(8 \%)$ were targeted at children and $240(92 \%)$ were not. Table 1 summarizes the nutritional content from the NIP of all products as well as their HSR score and the number of products displaying the Keyhole symbol. Child-targeted cereals contained more sugars, with a mean carbohydrate content of $78.3 \mathrm{~g}$ compared to $62.0 \mathrm{~g}$ per $100 \mathrm{~g}$ for the non-child-targeted group $(P<.001)$. This applied to sugar as well, where the mean in child-targeted products was nearly twice as high than in the non-child-targeted ones (22.3 g vs $12.8 \mathrm{~g}$ per $100 \mathrm{~g}, P<.001)$. Total fat, saturated fat, fiber, and protein were all lower in the child-targeted cereals compared to the cereals not targeted at children $(P<.001$ for all). There was no difference in salt content $(P=.61)$ between the groups. The main categories of cereals not targeted at children were muesli and granola, while cocoa-based and sweetened cereals accounted for the majority of child-targeted cereals (Table S1 in Multimedia Appendix 1).

Figure 1 shows that on-pack Keyhole labeling was aligned with products considered as "healthy" $(\geq 3.5)$ according to the HSR $(P<.001)$. No products with an HSR score $<4$ were labeled with the Keyhole symbol. However, $60 \%(n=92)$ of products with 4 stars or more were not Keyhole labeled. According to the HSR, there was no significant difference between cereals targeted at children and those that were not (mean 3.5 for the child-targeted group vs 3.8 for the non-child-targeted group, $P=.07$ ). 
Table 1. Nutritional overview of ready-to-eat breakfast cereals targeted at children $(n=21)$ compared to those not targeted at children $(n=240)$ and their estimated healthiness. The mean fiber amount in child-targeted cereals was based on 20 products since 1 product did not display its fiber content.

\begin{tabular}{|c|c|c|c|}
\hline Nutrition $^{\mathrm{a}}$ & Child-targeted cereals & Non-child-targeted cereals & $P$ value ${ }^{\mathrm{b}}$ \\
\hline Energy (kJ/100 g) & & & .18 \\
\hline Mean (SD) & $1628(68)$ & 1699 (202) & \\
\hline Median (IQR) & $1618(49)$ & $1647(225)$ & \\
\hline Total fat (g/100 g) & & & $<.001$ \\
\hline Mean (SD) & $3.0(2.8)$ & $10.5(9.6)$ & \\
\hline Median (IQR) & $2.3(1.5)$ & $7.6(12.8)$ & \\
\hline Saturated fat $(\mathrm{g} / \mathbf{1 0 0} \mathrm{g})$ & & & $<.001$ \\
\hline Mean (SD) & $0.8(0.8)$ & $2.6(3.0)$ & \\
\hline Median (IQR) & $0.6(0.6)$ & $1.8(3.0)$ & \\
\hline Carbohydrates (g/100 g) & & & $<.001$ \\
\hline Mean (SD) & $78.3(5.3)$ & $62.0(13.5)$ & \\
\hline Median (IQR) & $78.0(6.1)$ & $62.0(13.4)$ & \\
\hline Sugars $(\mathrm{g} / \mathbf{1 0 0} \mathrm{g})$ & & & $<.001$ \\
\hline Mean (SD) & $22.3(7.5)$ & $12.8(7.8)$ & \\
\hline Median (IQR) & $23.5(13.0)$ & $11.0(12.1)$ & \\
\hline Protein $(g / 100 g)$ & & & .002 \\
\hline Mean (SD) & $8.1(1.7)$ & $10.5(2.6)$ & \\
\hline Median (IQR) & $8.2(2.2$ & $10.0(3.2))$ & \\
\hline Fiber $(\mathrm{g} / \mathbf{1 0 0} \mathrm{g})$ & & & .01 \\
\hline Mean (SD) & $6.2(2.5)$ & $9.8(5.0)$ & \\
\hline Median (IQR) & $6.8(3.6)$ & $9.0(4.8)$ & \\
\hline Salt (g/100 g) & & & .61 \\
\hline Mean (SD) & $0.5(0.3)$ & $0.5(0.4)$ & \\
\hline Median (IQR) & $0.6(0.6)$ & $0.4(0.6)$ & \\
\hline HSR $^{c}$ score & & & .07 \\
\hline Mean (SD) & $3.5(0.5)$ & $3.8(0.9)$ & \\
\hline Median (IQR) & $3.8(1.0)$ & $4.0(1.5)$ & \\
\hline Keyhole symbol, n (\%) & $1(5)$ & $53(22)$ & .06 \\
\hline
\end{tabular}

${ }^{\mathrm{a}}$ Data are $\mathrm{n}(\%)$ for the categorical variable and mean (SD) and median (IQR) for continuous variables.

${ }^{\mathrm{b}}$ Comparison of child-targeted versus non-child-targeted breakfast cereals was analyzed with a Mann-Whitney $U$ test.

${ }^{\mathrm{c}}$ HSR: Health Score Rating. 
Figure 1. The calculated Health Star Rating (HSR) score of breakfast cereals in supermarkets in Sweden (light blue) and the HSR scores of packaged products displaying an on-pack Keyhole symbol (dark blue).

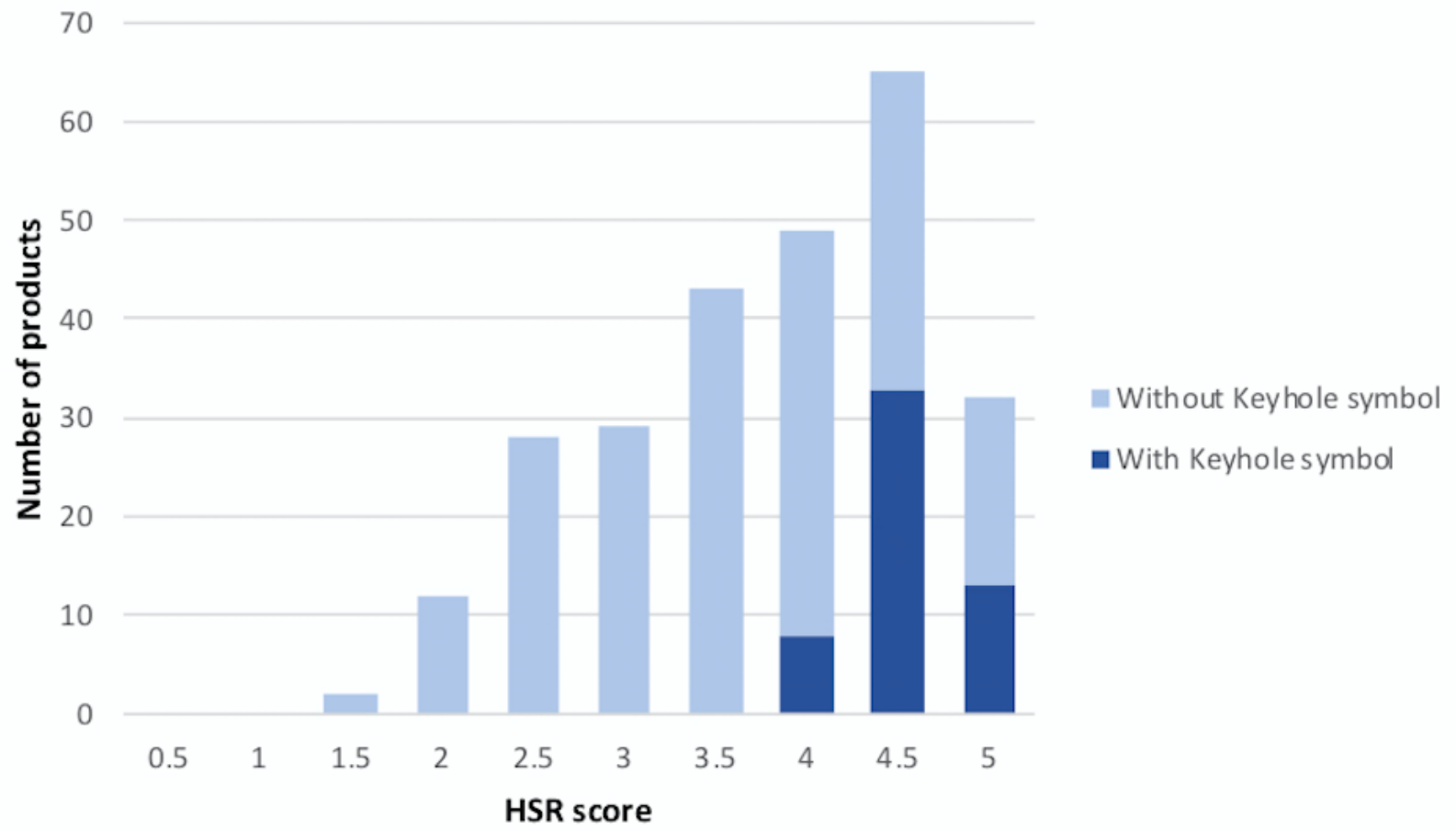

\section{Discussion}

\section{Principal Findings}

This study compared the healthiness of ready-to-eat breakfast cereals targeted at children to cereal products not specifically targeted at children across supermarkets in Sweden using the FoodSwitch platform. Despite lower levels of saturated fat, the child-targeted cereals were overall less healthy, according to the nutritional content. Child-targeted products had a greater amount of sugar, with a mean nearly 2 times higher than the cereals not branded toward children. Furthermore, they were lower in fiber and protein. Our results are in line with 3 similar studies conducted in Canada, Australia, New Zealand, Guatemala, and the United States [19-23]. However, this is the first study focusing on the healthiness of packaged cereal products in Europe. Interestingly, the number of products targeted at children is relatively small. Compared to the markets analyzed in other countries, we obtained the smallest ratio between child-targeted cereals and non-child-targeted ones [19-23]. A few cereals rated high in healthiness according to the HSR system although these had a high sugar content. This aligns with previous findings showing that the HSR rating algorithm does not sufficiently penalize products with a high added sugar content [24].

\section{Societal Relevance}

In a context where childhood obesity is at the heart of public health concerns, our findings are highly relevant. The direct link between added sugar intake and obesity is well established [25,26]. Recently, the American Heart Association reported associations between added sugars and cardiovascular disease risk factors among children at levels well below the actual average intake [27]. Therefore, sugar levels in foods intended for children should be as low as possible or at least be similar to products not branded toward children. Dietary fibers are known to improve satiety, and fiber consumption is associated with lower body weight [28]. Even though it has been shown that consumers of breakfast cereals are more likely to reach the recommended daily amount of fiber, there should be no difference in fiber between food items branded toward children and cereals not targeted at children [29]. The presence of more total fat and saturated fat in non-child-targeted products was probably due to cereal type. When the products were categorized, we noticed that granola and muesli accounted for a majority. These types of cereals often contain nuts and seeds, which are high in fat. Salt content was similarly low in all products. In fact, many sodium-reduction initiatives have been introduced as part of the European Union salt reduction framework [30]. One study showed a significant drop in salt levels in breakfast cereals in the United Kingdom [31]. We can assume that the same happened in Sweden since the brands sold in both countries are very similar; however, this would be possible to investigate in the future by using this study as the reference values for 2019 .

Marketing toward children often depicts cartoon characters to influence their food preferences [32]. In addition, children exposed to child-targeted cereals via TV commercials tend to have higher intake of these advertised cereals [33]. Problematically, products advertised to children are often of poor nutritional quality, as demonstrated in our study [34]. Unfortunately, packaging also affects parents, and parents being role models influence the eating habits of their children [35]. In fact, children depend on their parents' food choices. Finally, it has been shown that NIPs and front-of-pack labels can 
sometimes be difficult to interpret [36]. Therefore, there is a need to provide easy-to-understand solutions to better guide consumers and implement healthy dietary habits from the earliest age.

\section{Potential for the FoodSwitch Platform in Sweden}

A substantial part of the foods sold and eaten in high-income countries is preprepared packaged foods, and processed foods are largely responsible for an excessive intake of saturated fat, energy, added sugars, and sodium in the diet [37]. Thus, the food industry plays an increasingly important role in public health. The aim of the FoodSwitch platform is to change consumers' behaviors and legislators' actions. Front-of-pack labels are well established in influencing consumers toward healthier food choices. The Keyhole symbol used in Sweden was implemented 30 years ago. This front-of-pack logo is well known by Swedes as well as Scandinavians [38]. Although it is hard to assess its effect, it seems to positively affect the consumers' behavior [39]. Unfortunately, not all manufacturers use the logo even though it is free of charge. The criteria required to make a product eligible for the Keyhole symbol are numerous and vary according to product type. Thus, producers might not be aware when a product meets the standard. Moreover, displaying the symbol induces extra costs for new packaging. Manufacturers often prioritize the sales of their foods. Therefore, another reason for the lack of compliance to the Keyhole symbol might be that producers are not convinced of any added value by the logo on their products. Throughout our investigation, we realized that many products considered as "healthy" by the HSR system $(>3.5)$ did not display the Keyhole symbol. It is very likely that some of them were suitable to be branded with the Keyhole symbol.

Because of this, introducing the FoodSwitch app in Sweden could be of interest to Swedish consumers. First, it would allow a virtual front-of-pack labeling of all products (Figure 2). In fact, with information from the database, the app could generate the HSR score and the Traffic Lights label for any packaged product and suggest a healthier alternative. However, these two front-of-pack labeling systems used in the FoodSwitch app to direct consumers toward a healthier food choice are not used in Sweden. Fortunately, both the HSR and Traffic Lights label are self-explanatory and should not impede compliance of Swedish users to the mobile app's recommendations. In addition, it would be possible to add a filter on the app that would generate the Keyhole symbol. Second, the implementation of FoodSwitch in Sweden could pressure manufacturers to reformulate their products. If consumers choose healthier packaged foods, producers would have to adapt to evolving client demand. Finally, the FoodSwitch database would be a very useful tool for conducting research on many aspects of the packaged food market. Through crowdsourcing, the information from packaged foods are always updated, which allows a tracking of the nutritional composition of the food supply over time.

Figure 2. Screenshots of the Australian version of the FoodSwitch app displaying the estimated healthiness of products using Health Star Ratings (panels A and C) and Traffic Lights ratings (panels B and D) for the scanned products Dorset Cereals Really Nutty Muesli (panels A and B) and Kellogg's Special K Original (panels C and D), and suggestions for healthier options.
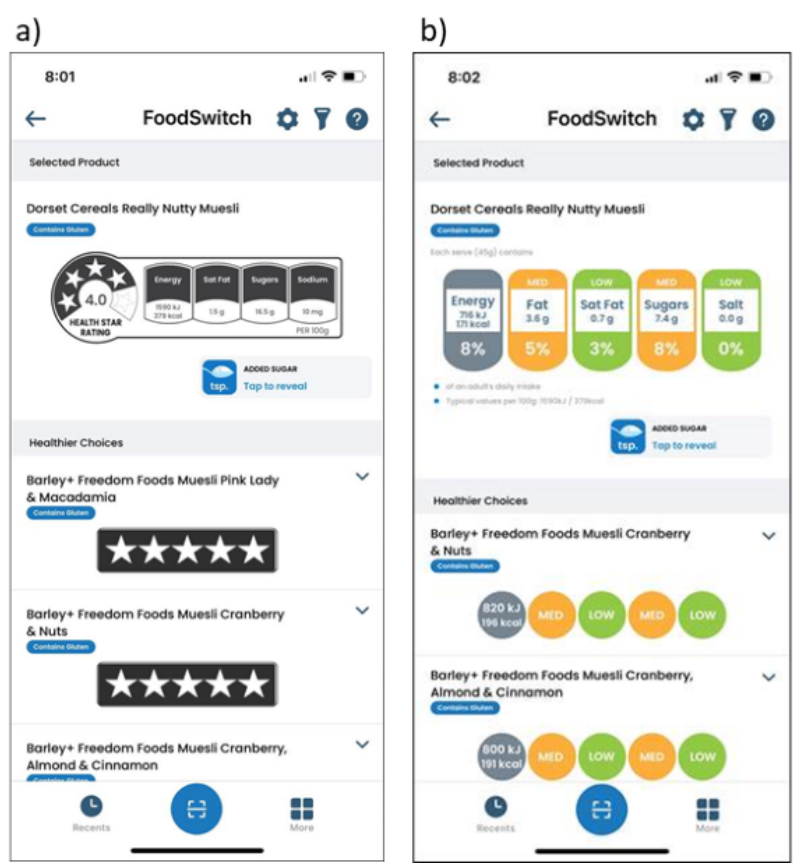

\section{Strengths, Limitations, and Future Directions}

We consider the conclusions drawn from our primary investigation to be reliable for the Swedish market because we visited the largest grocery retailers, representing $90 \%$ of market shares [16]. Another strength is the reliability of our data. During data collection, the data were double-checked by the collector c)

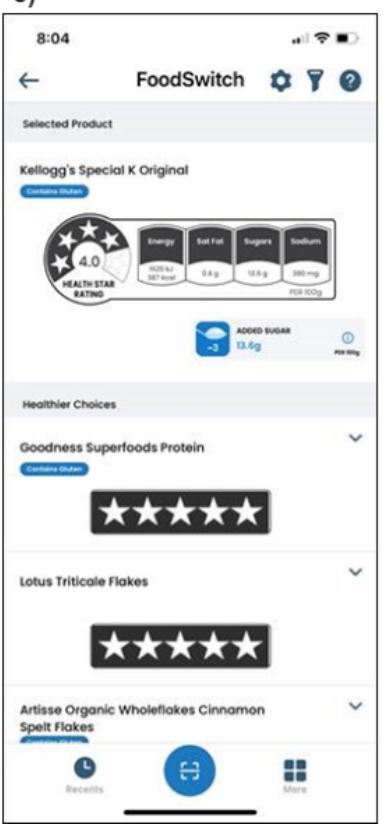

d)

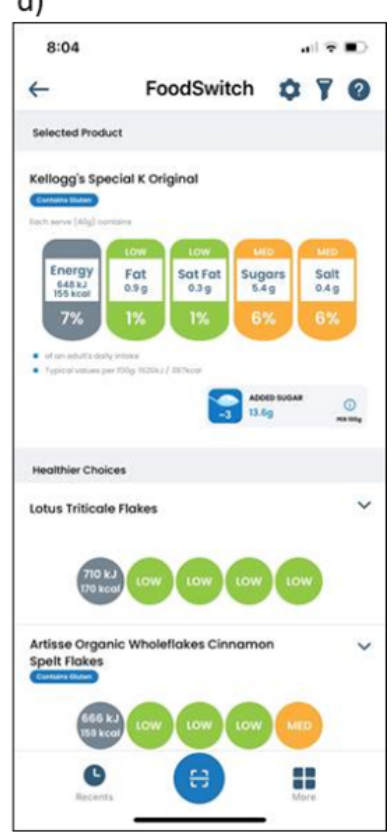

prior to data entry. Once entered, the data were checked by a second researcher.

Limitations include possible transcribing errors and, in some cases, minor discrepancies that can occur between the NIP information shown on the package and the real value [40]. In terms of the method of assessing the healthiness of products, 
in Europe, displaying fiber content on the package is not mandatory [41]; however, it is often included on the NIP and only one product in our sample did not display fiber content. Finally, another limitation is that our results are limited to the Swedish market.

A further research objective could be to expand this assessment of nutrition to all child-targeted products. Additionally, data collection of breakfast cereals can be redone to provide a longitudinal perspective.

\section{Conclusion}

In conclusion, we showed that the nutritional quality of ready-to-eat cereals targeted at children was overall not significantly unhealthier than ready-to-eat breakfast cereals not targeted at children. However, cereals targeted at children were high in sugar and low in fiber. Thus, we conclude that there is a need to improve the dietary quality of child-targeted breakfast cereals in Sweden.

\section{Authors' Contributions}

AM, CNM, BN, and KR contributed to the concept and rationale of the study. The data were collected and analyzed by AM. V-ML conducted the data review. AM and KR drafted the manuscript. All authors contributed to the interpretation of the results and the discussion, and reviewed and edited the manuscript.

\section{Conflicts of Interest}

None declared.

\section{Multimedia Appendix 1}

Ready-to-eat breakfast cereals in Swedish supermarkets in 2019, categorized according to the FoodSwitch platform categories. [DOCX File , $20 \mathrm{~KB}$-Multimedia Appendix 1]

\section{References}

1. Noncommunicable diseases: Childhood overweight and obesity. World Health Organization. 2020 Oct 10. URL: http:/ /www.who.int/dietphysicalactivity/childhood/en/ [accessed 2019-10-22]

2. Lobstein T, Jackson-Leach R. Estimated burden of paediatric obesity and co-morbidities in Europe. Part 2. Numbers of children with indicators of obesity-related disease. Int J Pediatr Obes 2006 Jan;1(1):33-41. [doi: 10.1080/17477160600586689] [Medline: 17902213 ]

3. Singh A, Mulder C, Twisk J, van Mechelen W, Chinapaw M. Tracking of childhood overweight into adulthood: a systematic review of the literature. Obes Rev 2008 Sep;9(5):474-478. [doi: 10.1111/j.1467-789x.2008.00475.x]

4. Juul F, Hemmingsson E. Trends in consumption of ultra-processed foods and obesity in Sweden between 1960 and 2010. Public Health Nutr 2015 Mar 25;18(17):3096-3107. [doi: 10.1017/s1368980015000506]

5. Costa CS, Del-Ponte B, Assunção MCF, Santos IS. Consumption of ultra-processed foods and body fat during childhood and adolescence: a systematic review. Public Health Nutr 2017 Jul 05;21(1):148-159. [doi: 10.1017/s1368980017001331]

6. Potvin Kent M, Rudnicki E, Usher C. Less healthy breakfast cereals are promoted more frequently in large supermarket chains in Canada. BMC Public Health 2017 Nov 13;17(1):877 [FREE Full text] [doi: 10.1186/s12889-017-4886-3] [Medline: 29132346]

7. van der Bend D, Lissner L. Differences and Similarities between Front-of-Pack Nutrition Labels in Europe: A Comparison of Functional and Visual Aspects. Nutrients 2019 Mar 14;11(3):626 [FREE Full text] [doi: 10.3390/nu11030626] [Medline: 30875797]

8. Regulations amending the National Food Agency's regulations (SLVFS 2005:9) on the use of a particular symbol. Swedish Food Agency. 2015 Jan 30. URL: http://extwprlegs1.fao.org/docs/pdf/swe199505.pdf [accessed 2019-11-05]

9. Health Star Rating System. Department of Health. Canberra: Australian Government URL: http://healthstarrating.gov.au/ internet/healthstarratin [accessed 2019-04-11]

10. Kelly B, Jewell J. What is the evidence on the policy specifications, development processes and effectiveness of existing front-of-pack food labelling policies in the WHO European Region? In: Health Evidence Network Synthesis Report, No. 61. Copenhagen: WHO Regional Office for Europe; 2018.

11. Svenskarna och internet 2018. Internetstiftelsen. 2018 Oct 3. URL: https://2018.svenskarnaochinternet.se/?referer=www. svenskarnaochinternet.se [accessed 2019-05-23]

12. Dunford E, Trevena H, Goodsell C, Ng KH, Webster J, Millis A, et al. FoodSwitch: A Mobile Phone App to Enable Consumers to Make Healthier Food Choices and Crowdsourcing of National Food Composition Data. JMIR Mhealth Uhealth 2014 Aug 21;2(3):e37 [FREE Full text] [doi: 10.2196/mhealth.3230] [Medline: 25147135]

13. Dunford E, Huang L, Peters S, Crino M, Neal B, Ni Mhurchu C. Evaluation of Alignment between the Health Claims Nutrient Profiling Scoring Criterion (NPSC) and the Health Star Rating (HSR) Nutrient Profiling Models. Nutrients 2018 Aug 10;10(8):1065. [doi: 10.3390/nu10081065]

14. Crino M, Sacks G, Dunford E, Trieu K, Webster J, Vandevijvere S, et al. Measuring the Healthiness of the Packaged Food Supply in Australia. Nutrients 2018 May 31;10(6):702 [FREE Full text] [doi: 10.3390/nu10060702] [Medline: 29857517] 
15. Coyle D, Ndanuko R, Singh S, Huang P, Wu J. Variations in Sugar Content of Flavored Milks and Yogurts: A Cross-Sectional Study across 3 Countries. Curr Dev Nutr 2019 Jun;3(6):nzz060 [FREE Full text] [doi: 10.1093/cdn/nzz060] [Medline: 31187086]

16. Sweden: market share of selected grocery retailers 2017. Statista. 2018. URL: https://www.statista.com/statistics/565650/ market-share-of-selected-grocery-retailers-in-sweden/ [accessed 2019-05-01]

17. Guide for Industry to the Health Star Rating Calculator. Commonwealth of Australia. 2019. URL: http://www. healthstarrating.gov.au/internet/healthstarrating/publishing.nsf/Content/E380CCCA07E1E42FCA257DA500196044/\$File/ Health-Star-Rating-system-Calculator-and-Style-Guide.pdf [accessed 2020-12-14]

18. Dunford E, Cobcroft M, Thomas M, Wu JH. Technical Report: Alignment of NSW Healthy Food Provision Policy with the Health Star Rating System. Sydney, NSW, Australia: NSW Ministry of Health; 2015.

19. Tong T, Rangan A, Gemming L. Evaluating the Nutritional Content of Children's Breakfast Cereals in Australia. Children (Basel) 2018 Jun 21;5(7):84 [FREE Full text] [doi: 10.3390/children5070084] [Medline: 29933610]

20. Devi A, Eyles H, Rayner M, Ni Mhurchu C, Swinburn B, Lonsdale-Cooper E, et al. Nutritional quality, labelling and promotion of breakfast cereals on the New Zealand market. Appetite 2014 Oct;81:253-260. [doi: 10.1016/j.appet.2014.06.019] [Medline: 24953195]

21. Soo J, Letona P, Chacon V, Barnoya J, Roberto CA. Nutritional quality and child-oriented marketing of breakfast cereals in Guatemala. Int J Obes (Lond) 2016 Jan 21;40(1):39-44. [doi: 10.1038/ijo.2015.161] [Medline: 26293234]

22. Potvin Kent M, Cameron C, Philippe S. The healthfulness and prominence of sugar in child-targeted breakfast cereals in Canada. Health Promot Chronic Dis Prev Can 2017 Sep;37(9):266-273 [FREE Full text] [doi: 10.24095/hpcdp.37.9.02] [Medline: 28902476]

23. Schwartz MB, Vartanian LR, Wharton CM, Brownell KD. Examining the nutritional quality of breakfast cereals marketed to children. J Am Diet Assoc 2008 Apr;108(4):702-705. [doi: 10.1016/j.jada.2008.01.003] [Medline: 18375229]

24. Dishonest health star ratings on Milo and Kellogg's cereals. CHOICE. 2016 Feb 15. URL: https://www.choice.com.au/ food-and-drink/nutrition/food-labelling/articles/nestle-milo-kelloggs-cereals-misuse-health-star-ratings [accessed 2021-06-07]

25. Te Morenga L, Mallard S, Mann J. Dietary sugars and body weight: systematic review and meta-analyses of randomised controlled trials and cohort studies. BMJ 2012 Jan 15;346:e7492. [doi: 10.1136/bmj.e7492] [Medline: 23321486]

26. de Ruyter JC, Olthof MR, Seidell JC, Katan MB. A Trial of Sugar-free or Sugar-Sweetened Beverages and Body Weight in Children. N Engl J Med 2012 Oct 11;367(15):1397-1406. [doi: 10.1056/nejmoa1203034]

27. Vos MB, Kaar JL, Welsh JA, Van Horn LV, Feig DI, Anderson CA, et al. Added Sugars and Cardiovascular Disease Risk in Children: A Scientific Statement From the American Heart Association. Circulation 2017 May 09;135(19):e1017-e1034. [doi: 10.1161/cir.0000000000000439]

28. Slavin JL. Position of the American Dietetic Association: health implications of dietary fiber. J Am Diet Assoc 2008 Oct;108(10):1716-1731. [doi: 10.1016/j.jada.2008.08.007] [Medline: 18953766]

29. Williams P. The benefits of breakfast cereal consumption: a systematic review of the evidence base. Adv Nutr 2014 Sep 15;5(5):636S-673S [FREE Full text] [doi: 10.3945/an.114.006247] [Medline: 25225349]

30. European Commission, Health and Consumers. Survey on Members States' Implementation of the EU Salt Reduction Framework. Luxembourg: Publications Office of the European Union; Mar 07, 2014.

31. Pombo-Rodrigues S, Hashem KM, He FJ, MacGregor GA. Salt and sugars content of breakfast cereals in the UK from 1992 to 2015. Public Health Nutr 2017 Feb 07;20(8):1500-1512. [doi: 10.1017/s1368980016003463]

32. Lapierre MA, Vaala SE, Linebarger DL. Influence of licensed spokescharacters and health cues on children's ratings of cereal taste. Arch Pediatr Adolesc Med 2011 Mar 07;165(3):229-234. [doi: 10.1001/archpediatrics.2010.300] [Medline: 21383272]

33. Longacre MR, Drake KM, Titus LJ, Harris J, Cleveland LP, Langeloh G, et al. Child-targeted TV advertising and preschoolers' consumption of high-sugar breakfast cereals. Appetite 2017 Jan 01;108:295-302 [FREE Full text] [doi: 10.1016/j.appet.2016.10.014] [Medline: 27746213]

34. Levin AM, Levin IP. Packaging of healthy and unhealthy food products for children and parents: The relative influence of licensed characters and brand names. J Consum Behav 2010 Sep 28;9(5):393-402. [doi: 10.1002/cb.326]

35. Yee AZH, Lwin MO, Ho SS. The influence of parental practices on child promotive and preventive food consumption behaviors: a systematic review and meta-analysis. Int J Behav Nutr Phys Act 2017 Apr 11;14(1):47 [FREE Full text] [doi: 10.1186/s12966-017-0501-3] [Medline: 28399881]

36. Kelly B, Hughes C, Chapman K, Louie JC, Dixon H, Crawford J, et al. Consumer testing of the acceptability and effectiveness of front-of-pack food labelling systems for the Australian grocery market. Health Promotion International 2009 Mar 31;24(2):120-129. [doi: 10.1093/heapro/dap012]

37. van Raaij J, Hendriksen M, Verhagen H. Potential for improvement of population diet through reformulation of commonly eaten foods. Public Health Nutr 2009 Mar;12(3):325-330. [doi: 10.1017/S1368980008003376] [Medline: 18671891]

38. Mørk T, Grunert KG, Fenger M, Juhl HJ, Tsalis G. An analysis of the effects of a campaign supporting use of a health symbol on food sales and shopping behaviour of consumers. BMC Public Health 2017 Mar 09;17(1):239 [FREE Full text] [doi: 10.1186/s12889-017-4149-3] [Medline: 28274208] 
39. Sjölin KL. Nordic Keyhole: Experience and challenges in Sweden, Norway, Denmark and Iceland [Presentation on the Internet]. Swedish National Food Agency. 2013 May 16. URL: https://www.who.int/nutrition/events/ 2013 FAO WHO workshop frontofpack nutritionlabelling presentation Sjolin.pdf?ua=1 [accessed 2019-05-02]

40. Jumpertz R, Venti CA, Le DS, Michaels J, Parrington S, Krakoff J, et al. Food label accuracy of common snack foods. Obesity (Silver Spring) 2013 Jan 12;21(1):164-169 [FREE Full text] [doi: 10.1002/oby.20185] [Medline: 23505182]

41. Regulation (EU) No 1169/2011 of the European Parliament and of the Council of 25 October 2011. Official Journal of the European Union. 2011 Nov 22. URL: http://eur-lex.europa.eu/LexUriServ/LexUriServ. do?uri=OJ:L:2011:304:0018:0063:EN:PDF [accessed 2019-05-02]

\section{Abbreviations \\ HSR: Health Star Rating \\ mHealth: mobile health \\ NIP: Nutrition Information Panel}

Edited by G Eysenbach, R Kukafka; submitted 13.01.20; peer-reviewed by Y Li, J Alvarez Pitti; comments to author 17.09.20; revised version received 19.10.20; accepted 07.05.21; published 22.07.21

Please cite as:

Mottas A, Lappi VM, Sundström J, Neal B, Mhurchu CN, Löf M, Rådholm K

Measuring the Healthiness of Ready-to-Eat Child-Targeted Cereals: Evaluation of the FoodSwitch Platform in Sweden

JMIR Mhealth Uhealth 2021;9(7):e17780

URL: https://mhealth.jmir.org/2021/7/e17780

doi: $\underline{10.2196 / 17780}$

PMID: 34292165

(C)Antoine Mottas, Veli-Matti Lappi, Johan Sundström, Bruce Neal, Cliona Ni Mhurchu, Marie Löf, Karin Rådholm. Originally published in JMIR mHealth and uHealth (https://mhealth.jmir.org), 22.07.2021. This is an open-access article distributed under the terms of the Creative Commons Attribution License (https://creativecommons.org/licenses/by/4.0/), which permits unrestricted use, distribution, and reproduction in any medium, provided the original work, first published in JMIR mHealth and uHealth, is properly cited. The complete bibliographic information, a link to the original publication on https://mhealth.jmir.org/, as well as this copyright and license information must be included. 